\title{
Retraction Note to: Estimation of Anticipated Performance Index and Air Pollution Tolerance Index and of vegetation around the marble industrial areas of Potwar region: bioindicators of plant pollution response
}

\author{
Mehwish Jamil Noor $\cdot$ Shazia Sultana $\cdot$ Sonia Fatima \\ Mushtaq Ahmad • Muhammad Zafar • Maliha Sarfraz • \\ Masour A. Balkhyour - Sher Zaman Saf • Muhammad Aqeel Ashraf
}

Published online: 1 March 2016

(C) Springer Science+Business Media Dordrecht 2016

\section{Retraction Note to: Environ Geochem Health}

(2015) 37:441-455

DOI 10.1007/s10653-014-9657-9

This article has been retracted by the Editor-in-Chief. After a thorough investigation carried out according to the Committee on Publication Ethics guidelines, we have strong reason to believe that the peer review process was compromised.

The online version of the original article can be found under doi:10.1007/s10653-014-9657-9.

\section{J. Noor $\cdot$ S. Sultana $\cdot$ S. Fatima}

Department of Environmental Sciences, Fatima Jinnah

Women University, Rawalpindi 46000, Pakistan

\section{Ahmad · M. Zafar}

Department of Plant Sciences, Quaid-i-Azam University,

Islamabad 45320, Pakistan

M. Sarfraz

Department of Physiology and Pharmacology, University of Agriculture, Faisalabad 38040, Pakistan

M. A. Balkhyour

Department of Environmental Sciences, King Abdulaziz

University, Jeddah 22254, Saudi Arabia

\section{S. Z. Safi}

Department of Medicine, Faculty of Medicine, University of Malaya, 50603 Kuala Lumpur, Malaysia

M. A. Ashraf ( $₫)$

Department of Geology, Faculty of Science, University of Malaya, 50603 Kuala Lumpur, Malaysia

e-mail: aqeelashraf@um.edu.my

M. A. Ashraf

Centre for Research in Waste Management, University of Malaya, 50603 Kuala Lumpur, Malaysia 